\title{
THE PROTECTIVE EFFECT OF SESAME OIL AGAINST RENAL TOXICITY INDUCED BY CCL4 IN EXPERIMENTAL MODEL
}

\author{
Rasha A. El-Tahan ${ }^{(1)}$, Trez N. Michel ${ }^{(2)}$, Nilly A. Shams ${ }^{(3)}$ and Sara A. Shaker ${ }^{(1)}$ \\ (1) Department of Biochemistry, Medical Research Institute, Alexandria University, Alexandria, Egypt. \\ ${ }^{(2)}$ Department of Physiology, Medical Research Institute, Alexandria University, Alexandria, Egypt. \\ ${ }^{(3)}$ Nutrition Department, High Institute of Public Health, Alexandria University
}

\section{ABSTRACT}

Objective: Renal toxicity is one of the most common kidney problems that occur when the body is subjected to drugs or chemical reagents as carbon tetrachloride (CCl4). The aim of present study was to investigate the protective effect of a daily oral dose of sesame oil on oxidative stress, lipid peroxidation and DNA damage associated renal injury induced by $\mathrm{CCl} 4$ injection. Renal injury was induced in rats by interaperitoneal injection of $10 \% \mathrm{CCl} 4$ dissolved in olive oil twice a week in a dose of $1 \mathrm{ml} / \mathrm{kg}$, another group of rats simultaneously received sesame oil orally at a dose of $1 \mathrm{ml} / \mathrm{kg}$ for six weeks. At the end of the experimental period, the protective effect of sesame oil was measured on kidney injury molecule (KIM-1), oxidative stress (malondialdehyde (MDA)), total antioxidant capacity (TAC) and DNA damage. The present study found that sesame oil inhibited CCl4-induced renal injury, lipid peroxidation, DNA damage and increased antioxidant capacity. It was found that co-administration of sesame oil along with $\mathrm{CCl} 4$ ameliorated the toxic effect of $\mathrm{CCl} 4$ which led to a significant decrease of urea, creatinine, MDA and significant increase in glutathione (GSH) levels, also decrease DNA fragmentation by reduced olive tail moment and the \% of tail DNA and decrease KIM1 expression. Co-administration of sesame oil along with $\mathrm{CCl} 4$ increased antioxidant capacity by increasing nuclear factor-erythroid-2-related factor (Nrf2) and TAC levels. We hypothesize that a daily sesame oil supplement attenuates oxidative stress associated renal injury by reducing oxygen free radicals and lipid peroxidation in $\mathrm{CCl} 4$ treated rats and increased antioxidant capacity.

Keywords: Glomerular filtration rate, glomerular hyperfiltration, renal functional reserve, renal plasma flow, chronic kidney disease.

\section{INTRODUCTION}

Nowadays, there is a growing interest in discovering the protective biological function of natural due to their antioxidative properties,safe use and their potential roles in intracellular and extracellular defense against lipid peroxides and oxygen radicals in response to oxidative stress. Sesame oil (SO) is one of these natural products that becomes a matter of choice for our investigation. ${ }^{(1)}$ Sesame oil (SO) is obtained from the Sesamum indicum L. seeds that belong to the family of Pedaliaceae. It is composed of about $50 \%$ lipids, $15 \%$ carbo-hydrates, $5 \%$ moisture, and $15 \%$ proteins. The oxidative stability of sesame oil is due to the presence of lignin compounds such as sesamol, sesamin, sesamolin and tocopherol. Furthermore, it offers lipid peroxidation, the best protection by increasing nonenzymatic and enzymatic antioxidants. ${ }^{(2,3)}$ In addition, sesame oil is rich in dietary fibre, vitamin B1 and abundant sources of magnesium, phosphorous, calcium, manganese, zinc and copper. ${ }^{(4)}$

Renal toxicity is a serious kidney problem that occurs when the body is exposed to chemical reagent or drugs. ${ }^{(5,6)}$ The increase of toxic chemicals and hazardous wastes in our environment has become man's most urgent environmental pollution problem. Carbon tetrachloride $\left(\mathrm{CCl}_{4}\right)$ was commonly used in chemical industry as a cleaning agent. (7) Among environmental toxins, $\mathrm{CCl}_{4}$ which is a non-polar compound, can dissolve well in non-polar compounds such as fats, oils and iodine. ${ }^{(8)} \mathrm{CCl}_{4}$ is a transparent, odorless and nonflammable material. Chronic exposure to carbon tetrachloride cause serious damage to the kidney, liver and increase the risk of cancer. ${ }^{(9)}$ Studies showed that $\mathrm{CCl}_{4}$ toxicity can result in free radical production in most of 
body tissues as kidney, liver, testis, lung, heart, brain and blood. ${ }^{(10,11)} \mathrm{CCl}_{4}$ is decomposed into trichloromethyl $\left(\mathrm{CCl}_{3}{ }^{\circ}\right)$ and trichloromethyl peroxyl $\left(\mathrm{Cl}_{3} \mathrm{COO}\right)^{-}$radicals by the cytochrome oxidase enzyme complex. ${ }^{(12)} \mathrm{CCl}_{4}$ is a nonthreshold multitargeted toxicant that causes alterations in different organs of the body, such as nephrotoxicity, ${ }^{(13,}$ 14) cardiotoxicity, ${ }^{(15)}$ and hematotoxicity. ${ }^{(16)}$

Nuclear factor-erythroid-2-related factor 2 (Nrf2) has been found to be a critical transcription factor that binds to the antioxidant response element (ARE) in the promoter region of genes encoding antioxidants in several types of cells and tissues. ${ }^{(17)}$ The Nrf2-mediated regulation of cellular antioxidant and anti-fibrosis machinery plays an important role in the defence against oxidative stress. ${ }^{(18)} \mathrm{Nrf} 2$ is held as an inactive complex bound to a repressor molecule known as Kelch-like ECHassociated protein1 (Keap1) in the cytoplasm. Under oxidative stress, Nrf2 Keap1-mediated repression unbounds Nrf2 and Keap1 in cytoplasm. Nrf2 translocates into nucleus and binds to the ARE site. ${ }^{(19)}$ Therefore, activating Nrf2 has been recognized as one of the most important and promising molecular targets for protecting cells from oxidative stress and inflammatory insult. ${ }^{(20)}$

The kidney injury molecule-1 (KIM-1) has important roles in kidney function in humans and rodents. ${ }^{(21)} \mathrm{KIM}-$ 1 , also known as mucin-domain-containing molecule-1 (TIM-1) and T-cell immunoglobulin, was first proposed to have a role in restoration after a kidney injury, when it was found to be markedly upregulated in the proximal tubular cells of rats after ischaemic injury. ${ }^{(22)}$ It was demonstrated that chronic expression of KIM-1 in renal epithelial cells of transgenic mice led to tubular interstitial fibrosis and inflammation, whereas mice with a truncated form of KIM-1 were protected from fibrosis. ${ }^{(23)}$

Our study aimed to evaluate the protective effect of a daily oral administration of sesame oil against oxidative stress, lipid peroxidation and DNA damage associated with renal injury induced by $\mathrm{CCl}_{4}$ injection and study the ameliorated effect of sesame oil on antioxidant capacity.

\section{MATERIAL AND METHODS:}

\section{Experimental animals:}

In this study, 40 male Wistar rats, weighing between $180 \pm 20 \mathrm{~g}$, were used. After randomization into various groups, the rats were acclimatized for a period of 7 days under standard conditions at room temperature $\left(25 \pm 3{ }^{\circ} \mathrm{C}\right)$ with $12 \mathrm{hr} / 12 \mathrm{hr}$ light/dark cycles. All animals were fed under strict hygienic conditions with rodent pellet diet and water ad libitum. The animal experiments ethics committee approved the study (Approval number: AU012-19-03-19-3-4). The study was conducted in accordance with the Guide for the Care and Use of Laboratory Animals in Medical Research Institute.

\section{Experimental design:}

Rats were divided into four groups each contained 10 rats; Group 1, rats were fed on the standard diet and were served as a control group. Group 2, rats were orally given sesame oil $1 \mathrm{ml} / \mathrm{kg}$ of body weight twice a week for six weeks. (24) Group 3: rats were injected intraperitonealy with $1 \mathrm{ml} / \mathrm{kg}$ of body weight of $10 \% \mathrm{CCl}_{4}$ dissolved in olive oil twice a week for six weeks. ${ }^{(25)}$ Group 4: rats were injected with $\mathrm{CCl}_{4}$ combined with an oral administration of sesame oil twice a week for six weeks.

\section{Biochemical investigation:}

\section{Renal function tests}

All rats were sacrificed by decapitation under anesthesia using ketamine $10 \% 75 \mathrm{mg} / \mathrm{kg}$ of body weight and xylazine $10 \mathrm{mg} / \mathrm{kg}$ of body weight. ${ }^{(26)}$ The blood was collected and serum was separated by centrifugation at $3000 \mathrm{rpm}$ for $10 \mathrm{~min}$. Serum urea and creatinine were assessed calorimetrically using commercial diagnostic kits (Spectrum, Egypt).

\section{Kidney homogenates}

After decapitation the rats' kidney tissues were dissected out, washed with ice-cold normal saline to completely remove all the blood cells. Then, samples were cut into small pieces where one piece was placed in $50 \mathrm{mM}$ Tris buffer (pH 7.4) and was homogenized using Heidolph (Silent Crusher) homogenizer to obtain $10 \%$ homogenates. The homogenate was centrifuged at 3000 rpm for $15 \mathrm{~min}$ and the supernatant was collected, transferred to an eppendorf tube and centrifuged at 12000 rpm for $20 \mathrm{~min}$. The whole homogenate was used for the determination of Malondialdehyde (MDA; as a lipid peroxidation marker) and the supernatant was used for the determination of total antioxidant capacity (TAC), and the activity of glutathione -S-transferase (GST).

\section{Determination of MDA level:}

Lipid peroxidation in the kidney homogenate was expressed in terms of thiobarbituric acid reactive substances (TBARS) by measuring MDA levels, spectrophotometrically in kidney homogenates according to Draper and Hadley. ${ }^{(27)}$ Briefly, $0.1 \mathrm{ml}$ of the sample was mixed with $0.75 \mathrm{ml}$ acetic acid, $0.75 \mathrm{ml}$ of thiobarbituric (TBA) and $0.3 \mathrm{ml}$ of distilled water, and heated in a boiling water bath for 1 hour. An aliquot of $0.5 \mathrm{ml}$ of distilled water was added to each tube followed by the addition of $2.5 \mathrm{ml} \mathrm{n}$-butanol. The pink-colored chromogen formed by the reaction of TBA with MDA, was extracted by n-butanol and measured at $532 \mathrm{~nm}$. MDA levels were expressed as nmol/mg protein.

\section{Determination of GST activity:}

GST catalyzes the conjugation reaction with glutathione in the first step of mercapturic acid synthesis. The activity of GST was determined by the method modified by Carmagnol et al. (28) The GST-catalyzed conjugation of GSH with 1-chloro-2, 4-dinitrobenzene (CDNB) that was measured spectrophotometrically at $340 \mathrm{~nm}$. One unit of enzyme activity was defined as the amount of enzyme which catalyzes the formation of $1 \mu$ mole of S-conjugate per minute under the assay conditions. ${ }^{28)}$

\section{Determination of TAC:}

Based on the oxidation of intracellular anti-oxidants with iron (III) in acidic medium, the TAC in the kidney was 
assayed with a commercially available assay kit (Cat No. A015-1; Nanjing Jiancheng Bio Co., Nanjing, China). The TAC of the samples was measured according to the manufacturer's protocol. One unit of TAC was defined as the capability of increasing the optical density value at $520 \mathrm{~nm}$ by 0.01 per $\mathrm{mg}$ protein per min at $37^{\circ} \mathrm{C}$.

Determination of total protein concentration; by the method of Lowry et al. ${ }^{(29)}$

\section{Determination of DNA damage by the comet assay:}

DNA damage was measured using a single-cell gel electrophoresis technique (comet assay) where $0.5 \mathrm{~g}$ of crushed samples were transferred to $1 \mathrm{ml}$ ice-cold PBS. This suspension was stirred for $5 \mathrm{~min}$ and filtered. The cell suspension $(100 \mu \mathrm{l})$ was mixed with $600 \mu \mathrm{l}$ of low melting agarose $(0.8 \%$ in PBS) where $100 \mu$ of this mixture was spread on the completely frosted microscope slide that was precoated with normal melting point agarose $(0.5 \%)$. The coated slides were immersed in lyses buffer [0.045mol/1 Tris/Borate/EDTA (TBE), pH 8.4, containing $2.5 \%$ Sodium dodecyl sulphate (SDS)] for 15 min. The slides were then placed in an electrophoresis chamber containing the same TBE buffer, but without SDS. The electrophoresis conditions were $2 \mathrm{~V} / \mathrm{cm}$ for 2 min and $100 \mathrm{~mA}$. After electrophoresis, the slides were washed in a neutralization buffer $(0.4 \mathrm{M}$ Tris hydrochloride, $\mathrm{pH} 7.5)$. Finally, the slides were stained with ethidium bromide $20 \mu \mathrm{g} / \mathrm{ml}$ at $4^{\circ} \mathrm{C}$. For visualization of DNA damage, observations of ethidium bromidestrained DNA were made using a $\times 40$ objective on a fluorescent microscope [with excitation filter 420-490 nm linked to a camera (Olympus)]. DNA damage was evaluated by Olive tail moment and the percentage of DNA in the tail (\%Tail DNA) from 50 cells in each sample using a computer-based image analysis system. ${ }^{(30)}$

\section{One-step quantitative real-time polymerase chain reaction (qRT-PCR):}

Total RNA was extracted from kidney tissues with GF-1 Total RNA Extraction Kit (Vivantis, Malaysia) according to the manufacturer's instructions. qRT-PCR assays were performed with Rotor-Gene SYBR Green RT-PCR Kit (Qiagen ${ }^{\circledR}$, Valencia, CA, USA) on Rotor-Gene Q, (Qiagen ${ }^{\circ}$, Valencia, CA, USA) qRT-PCR amplification conditions started with initial reverse transcription for the synthesis of cDNA for $10 \mathrm{~min}$ at $55^{\circ} \mathrm{C}$ and the resultant cDNA was then amplified by 40 cycles of PCR as follows: denaturation at $95^{\circ} \mathrm{C}$ for $5 \mathrm{~s}$, annealing at $55^{\circ} \mathrm{C}$ for $15 \mathrm{~s}$, and extension at $60^{\circ} \mathrm{C}$ for $15 \mathrm{~s}$. The housekeeping gene glyceraldehyde-3-phosphate dehydrogenase (GAPDH) was used as a reference gene for normalization. Primers used for rat genes were as follows:

Nrf2:F:5'-CATTTGTAGATGACCATGAGTCGC-3', R:5'CGGTGGGTCTCCGTAAATGG-3', ${ }^{(31)}$

KIM-1: F: 5'-CGCAGAGAAACCCGACTAAG-3', R: 5'-CAAAGCTCAGAGAGCCCATC-3'. ${ }^{(32)}$

GAPDH: F: 5'-CAACTCCCTCAAGATTGTCAGCAA-3', R: 5'-GGCATGGACTGTGGTCATGA-3'. ${ }^{(33)}$
The values of threshold cycle $(C t)$ were determined by Rotor-Gene Q-Pure Detection version 2.1.0 (build 9) (Qiagen®, Valencia, CA, USA). For each gene, the relative change in mRNA in samples was determined using the $2^{-\Delta \Delta C \mathbf{t}}$ method and normalized to the housekeeping gene GAPDH.

\section{STATISTICAL ANALYSIS:}

Data were analyzed using SPSS software package version 18.0 (SPSS, Chicago, IL, USA). The data were expressed as mean \pm SD. Comparisons between different groups were made using one way ANOVA.

\section{RESULTS:}

Effect of $\mathrm{CCl}_{4}$ and $\mathrm{SO}$ on renal toxicity and oxidative stress:

The results of the present study showed that $\mathrm{CCl}_{4}$ cause renal toxicity indicated by significant increase in urea and creatinine levels as well as oxidative stress indicated by significant increase of MDA level and significant decrease in GSH level compared to control group. The coadministration of sesame oil along with $\mathrm{CCl}_{4}$ ameliorated the toxic effect of $\mathrm{CCl}_{4}$ which led to significant decrease of urea and creatinine levels compared to the rats administered with $\mathrm{CCl}_{4}$. Sesame oil showed a significant reduction in MDA level and significant increase in GSH level compared to control. (Table 1)

\section{Effect of $\mathrm{CCl}_{4}$ and $\mathrm{SO}$ on $\mathrm{Nrf} 2$ and TAC:}

The present results revealed a significant increase in gene expression of Nrf2 in group treated with SO compared to control group. On the other hand, $60 \%$ reduction in the expression of this gene was observed in rats treated with $\mathrm{CCl}_{4}$ compared to control group, while the coadministration of sesame oil along with $\mathrm{CCl}_{4}$ ameliorated this effect as indicated by significant increase in $\mathrm{Nrf} 2$ gene expression. (Figure 1) The current results showed a significant increase in TAC level in rats treated with SO compared to control group. On the other hand, there was a significant decrease in TAC level in rats treated with $\mathrm{CCl}_{4}$ compared to control group, while the co-administration of sesame oil along with $\mathrm{CCl}_{4}$ ameliorated this effect as shown by the significant increase in TAC level.(Figure 2)

\section{Effect of $\mathrm{CCl}_{4}$ and $\mathrm{SO}$ on DNA damage}

DNA damage was detected in rats treated with $\mathrm{CCl}_{4}$ being determined by comet assay which causes significant increase in olive tail moment and the percentage $(\%)$ of tail DNA while co-administration of sesame oil and $\mathrm{CCl}_{4}$ causes significant decrease in olive tail moment and the \% of tail DNA compared to group treated with $\mathrm{CCl}_{4}$. (Figure 3)

\section{Effect of $\mathrm{CCl}_{4}$ and $\mathrm{SO}$ on $\mathrm{KIM}-1$ gene expression}

The present study showed a significant decrease in KIM-1 gene expression in rats treated with SO with 3 fold increase in this gene expression observed in rats treated with $\mathrm{CCl}_{4}$ compared to control group. On the other hand, the co-administration of sesame oil along with $\mathrm{CCl}_{4}$ ameliorated this effect by significant decrease in KIM-1 gene expression. (Figure 
Table 1: Serum levels of urea, creatinine and MDA and activity of GSH in kidney tissue in control rats and rats treated with sesame oil, $\mathrm{CCl}_{4}$ and rats co-administered with $\mathrm{CCl}_{4}$ and sesame oil

\begin{tabular}{|c|c|c|c|c|}
\hline Parameters & $\begin{array}{c}\text { Control } \\
(n=10)\end{array}$ & $\begin{array}{c}\text { Sesame oil } \\
(n=10)\end{array}$ & $\begin{array}{c}\mathrm{CCl}_{4} \\
(\mathrm{n}=10)\end{array}$ & $\mathrm{CCl}_{4}+$ Sesame oil $(\mathrm{n}=10)$ \\
\hline $\begin{array}{c}\text { Urea } \\
(\mathrm{mg} / \mathrm{dl})\end{array}$ & $Y \varepsilon . r \pm 1 . Y I$ & r.I \pm 1.1 & $\begin{array}{c}42.5 \pm 2.8 \\
\mathrm{ab}\end{array}$ & $\begin{array}{c}32 \pm 1.7 \\
\text { abc }\end{array}$ \\
\hline $\begin{array}{l}\text { Creatinine } \\
\text { (mg/dl) }\end{array}$ & $\cdot \wedge \prime \pm \cdot \cdot \wedge \prime$ & $\cdot \wedge\urcorner \pm \cdot .0$ & $\begin{array}{c}1.4 \pm 0.16 \\
\mathrm{ab}\end{array}$ & $\begin{array}{c}1.1 \pm 0.02 \\
\mathrm{abc}\end{array}$ \\
\hline $\begin{array}{c}\text { MDA } \\
(\mathrm{nmol} / \mathrm{ml})\end{array}$ & $2.65 \pm 0.3$ & $\begin{array}{c}3.8 \pm 0.3 \\
\mathrm{a}\end{array}$ & $\begin{array}{c}7.2 \pm 2.4 \\
\mathrm{ab}\end{array}$ & $\begin{array}{c}4.5 \pm 0.6 \\
\mathrm{abc}\end{array}$ \\
\hline $\begin{array}{c}\text { GSH } \\
(\mathrm{nmol} / \mathrm{ml})\end{array}$ & ov.1 $\pm r .9$ & $\begin{array}{c}65.8 \pm 4.1 \\
\mathrm{a}\end{array}$ & $\begin{array}{c}30.3 \pm 3.5 \\
\mathrm{ab}\end{array}$ & $\begin{array}{c}42.6 \pm 2.6 \\
\text { abc }\end{array}$ \\
\hline
\end{tabular}

Data presented as Mean \pm SD $(n=10)$; statistical analysis was done using ANOVA test and the statistical significance was calculated at $\mathrm{p}<0.05$

a: significantly different from control group.

b: significantly different from rats administrated with Sesame oil group.

c: significantly different from rats administrated with $\mathrm{CCl}_{4}$ and sesame oil.

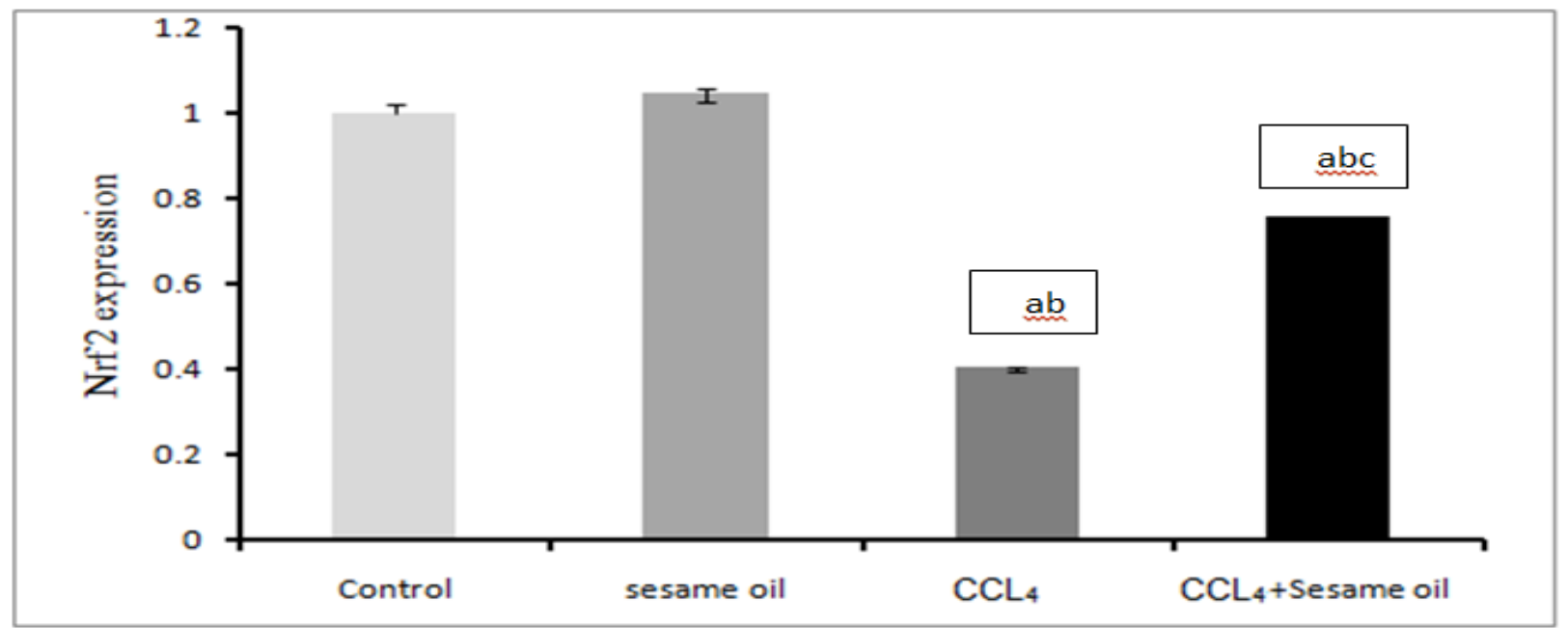

Fig. (1): Nrf2 expression in control rats and rats treated with sesame oil, $\mathbf{C C l}_{\mathbf{4}}$ and co-administrated with $\mathrm{CCl}_{4}$ and sesame oil Data presented as Mean \pm SD $(n=10)$; statistical analysis was done using ANOVA test and the statistical significance was calculated at $\mathrm{p}<0.05$

a: significantly different from control group.

b: significantly different from rats administrated with Sesame oil group.

c: significantly different from rats administrated with $\mathrm{CCl}_{4}$ and sesame oil.

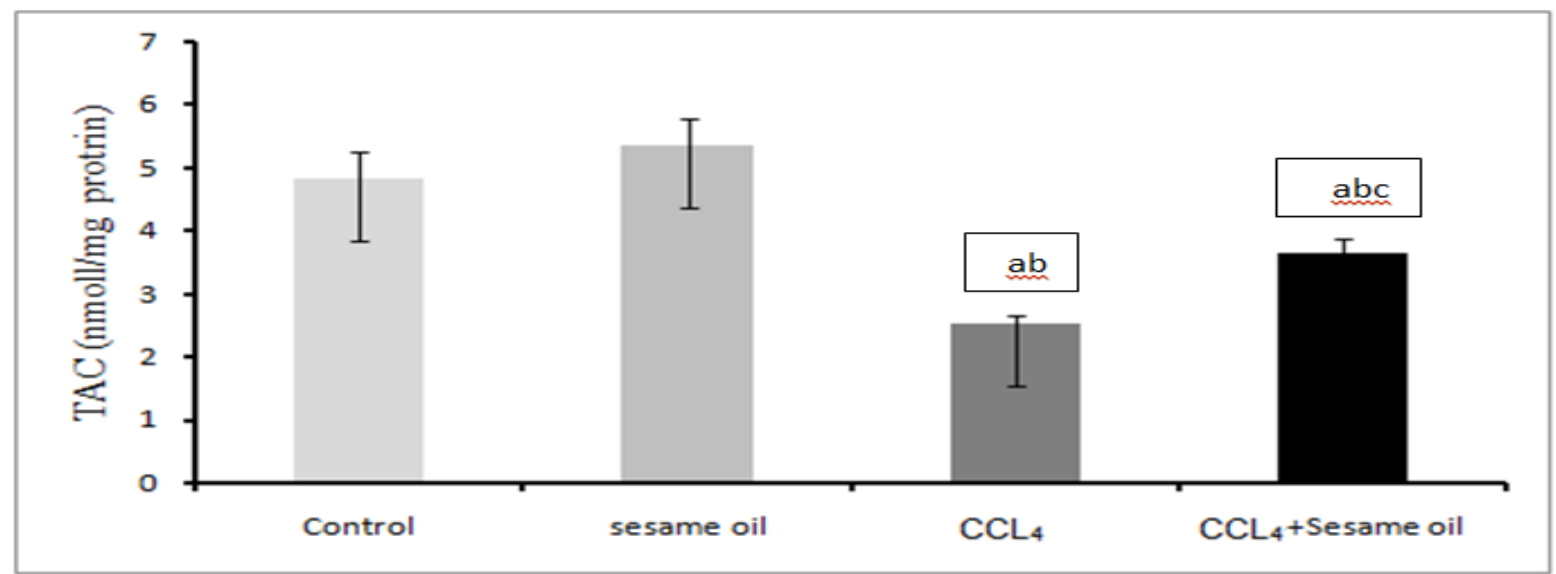

Fig. (2); TAC content in control rats and rats treated with sesame oil, $\mathrm{CCl}_{4}$ and co-administrated with $\mathrm{CCl}_{4}$ and sesame oil 

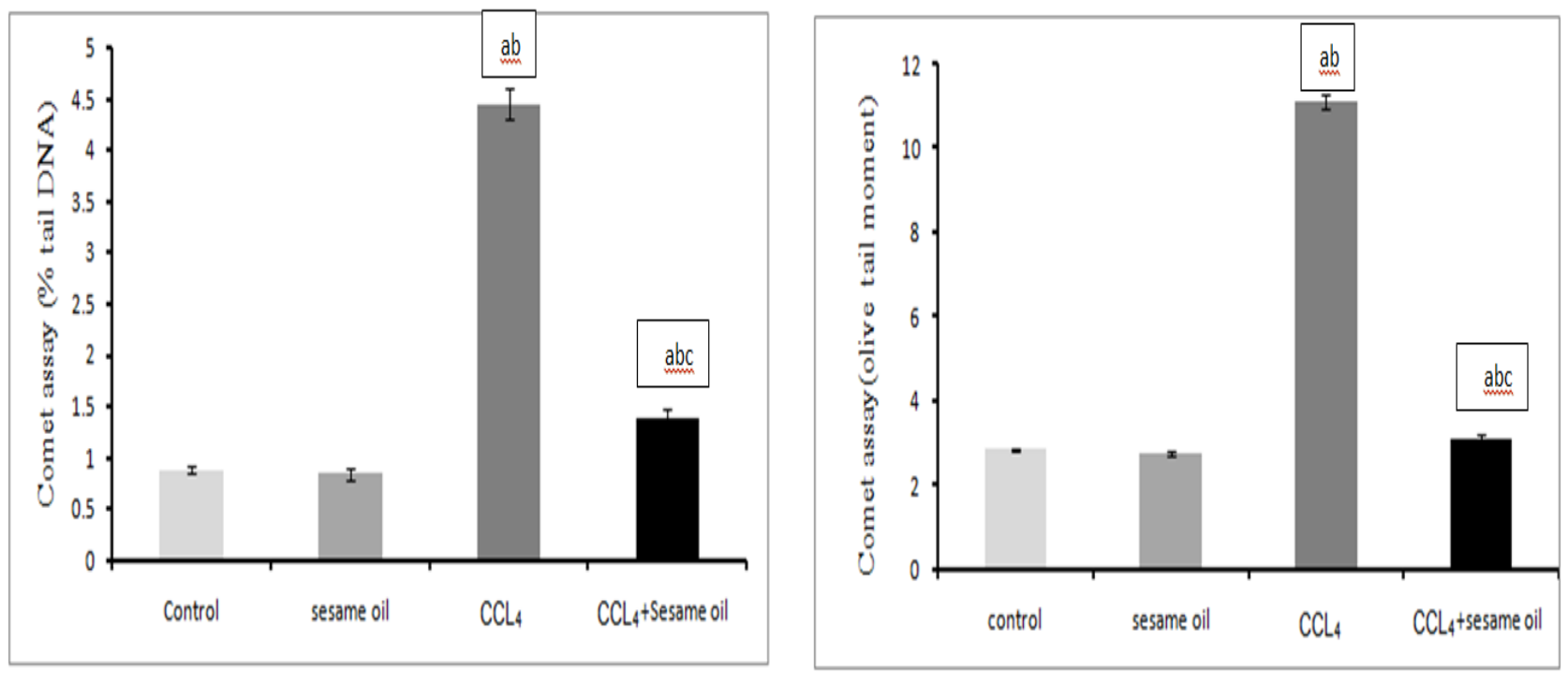

Fig. (3); Tail intensity (\% of total genomic DNA found in the tail of the comet) and tail moment measured with comet assay in kidney cells in control rats and rats treated with sesame oil, $\mathrm{CCl}_{\mathbf{4}}$ and co-administrated $\mathrm{CCl}_{\mathbf{4}}$ and sesame oil

Data presented as Mean \pm SD $(n=10)$; statistical analysis was done using ANOVA test and the statistical significance was calculated at $\mathrm{p}<0.05$

a: significantly different from control group.

b: significantly different from rats administrated with Sesame oil group.

c: significantly different from rats administrated with $\mathrm{CCl}_{4}$ and sesame oil.

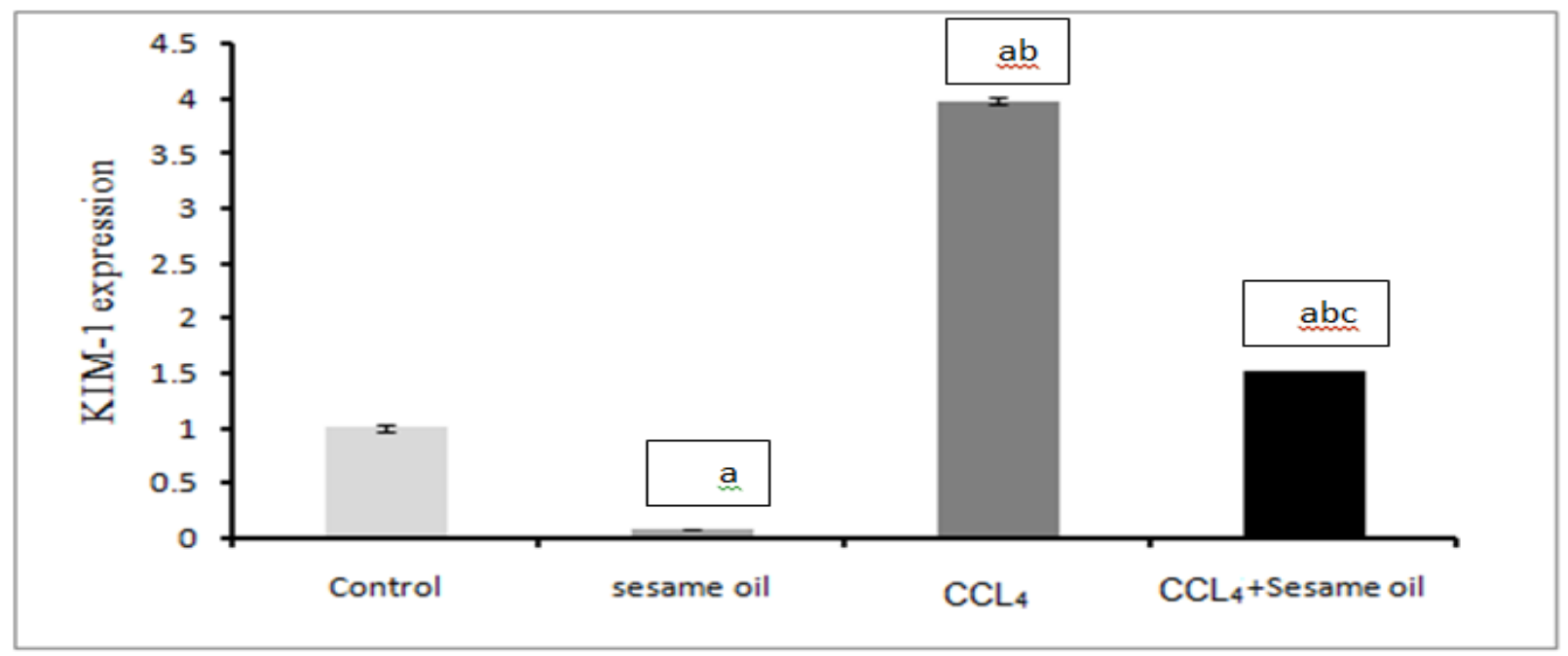

Fig. (4); KIM-1 expression in control rats and rats treated with sesame oil, $\mathrm{CCl}_{4}$ and co-administrated with $\mathrm{CCl}_{4}$ and sesame oil

Data presented as Mean \pm SD $(n=10)$; statistical analysis was done using ANOVA test and the statistical significance was calculated at $\mathrm{p}<0.05$

a: significantly different from control group.

b: significantly different from rats administrated with Sesame oil group.

c: significantly different from rats administrated with $\mathrm{CCl}_{4}$ and sesame oil.

\section{DISCUSSION:}

Antioxidants are important substances which can protect the body from injuries caused by free radicals. This antioxidant capacity of chemicals can be beneficial for development of novel medicines against degenerative diseases. Based on the rising interest in free radicals biology and the utility of antioxidants in protection against oxidative stress, antioxidants are regarded as a tool to prevent or slow down the progression of conditions assigned to oxidative stress. ${ }^{(34)}$ A substantial number of herbal formulations has been shown to have 
therapeutic properties against several life threatening diseases. ${ }^{(35)}$

Chemical- and drug-induced renal toxicity is a major cause of death worldwide. Previous published research studies have reported that $\mathrm{CCl}_{4}$ exposure causes damage to the kidney due to enhanced production of reactive oxygen species (ROS). ${ }^{(36)}$ Several natural products have been demonstrated to possess antioxidant properties and are capable of suppressing the generation of free radicals to protect acute kidney damage. (37) The present investigations showed that administration of $\mathrm{CCl}_{4}$ to rats significantly increased the levels of creatinine and urea whereas, the co-administration with sesame oil significantly reduced these levels.

Many research studies have demonstrated that $\mathrm{CCl}_{4}$ poisoning is the main source of free radical production in many tissues such as liver, kidney, lungs, brain, and blood. ${ }^{(38,39)}$ It has also been reported that after the administration of $\mathrm{CCl}_{4}$ to rats; it is distributed at higher concentration in the kidney than in the liver ${ }^{(39)}$, since the kidney has higher affinity for $\mathrm{CCl}_{4}$. The most common free radicals from $\mathrm{CCl}_{4}$ is trichloromethyl radical $\left(\mathrm{CCl}_{3}{ }^{\circ}\right)$ and trichloromethyl peroxyl radical $\left(\mathrm{CCl}_{3} \mathrm{O}_{2}{ }^{\circ}\right)$. These radicals bind to intracellular protein, lipids of cell membrane, and DNA resulting in protein denaturation, lipid peroxidation, and oxidative DNA damage that leads to cell death. Lipid peroxidation is one of the important markers of oxidative stress. ${ }^{(40)}$ The level of MDA was found to be significantly increased in kidney tissue after administration of $\mathrm{CCl}_{4}$. The co-administration of sesame oil has shown a significant decrease in MDA level. This may be due to antioxidant properties of sesame oil which scavenges free radicals thereby inhibiting lipid peroxidation.

Glutathione (GSH) is an antioxidant which has an important role in cessation of any cellular damage caused by free radicals and peroxides. ${ }^{41)}$ Our results showed a significant reduction in GSH level in rats treated with $\mathrm{CCl}_{4}$, which may be explained on the role of $\mathrm{CCl}_{4}$ in impairment of $\mathrm{H}_{2} \mathrm{O}_{2}$ clearance and promotion of hydroxyl radical $\left({ }^{\circ} \mathrm{OH}\right)$ formation which leads to oxidative stress. (42) The effective restoration of lipid peroxidation and enhancement of glutathione content were observed after the co-administration of sesame oil.

There is increasing evidence that oxidative stress and inflammation are integrated contributing factors to kidney damage. Recent studies have determined the role of Nrf2 signaling in renal protection against oxidative damage, and in alteration of inflammatory response. So that, plantderived Nrf2 activators such as curcumin have demonstrated their safety and health benefits in human subjects. Therefore, Nrf2 activators substances have antioxidant and anti-inflammatory activities in kidney damage that may be a promising strategy to ameliorate or retard kidney dysfunction. ${ }^{(43)} \mathrm{Nrf} 2$ level was significantly decreased after administration of $\mathrm{CCl}_{4}$, whereas coadministration of sesame oil restored the decreased level of Nrf2.

Paradoxically, TAC assays do not measure total antioxidant capacity but they measure the low molecular weight, chain breaking antioxidants, without the donation of metal binding proteins and antioxidant enzymes. Biological fluids contain large number of compounds with chain breaking antioxidant activity, as thiol, ascorbate, bilirubin, and urates in the aqueous phase and $\alpha$-tocopherol, flavonoids, and carotenoids in the lipid phase. (44) Our study showed that TAC levels were significantly decreased in rats treated with $\mathrm{CCl}_{4}$ while coadministration of sesame oil showed significant increase in TAC levels.

By using agarose gel electrophoresis, DNA laddering (DNA fragmentation) was undetectable in the kidney of the control rats. The DNA intact band appears to be condensed near the application point with no DNA smearing, suggesting no DNA fragmentation. ${ }^{(45)}$ On the other hand, $\mathrm{CCl}_{4}$-treatment resulted in massive DNA fragmentations with a subsequent formation of a DNA smear on agarose gel, a hallmark feature of necrosis without ladder formation, suggesting $\mathrm{CCl}_{4}$-induced renal cell damage. Sesame oil was found to be effective in preventing this $\mathrm{CCl}_{4}$-induced smear formation.

The kidney injury molecule-1 (KIM-1) is a transmembrane protein with obvious advantages as a new marker for the early diagnosis of acute kidney injury 17(AKI17). In normal kidney tissue, it is virtually not expressed, but it is expressed in the endothelial cells of the proximal convoluted tubules at moderate to high levels during the early stages of nephrotoxic injury or renal ischemic. It is also correlated with the severity of kidney injury. Moreover, it has a strong specificity, especially for ischemic or nephrotoxic acute kidney injury (AKI), and is rarely expressed in other organs. (1) Our study showed that administration of sesame oil in normal rats showed a marked decrease in KIM-1 gene expression, on the other hand, $\mathrm{CCl}_{4}$ showed a significant increase in its gene expression, whereas co-administration markedly decreased its expression. ${ }^{(46)}$

In chronic kidney disease (CKD), nutrition and diet play an important role both in prevention of disease progression and in symptom management. Sesame oil is non-toxic nutritional oil, used in the diet in most countries and is effective against various disease models. It protects against multi-organ failure, by acting as disease prevention and symptom managing agent. Sesame oil is advantageous over chemical clinical management of CKD (20) and contains vitamins, glycerol esters of fatty acids, and lignans such as sesamol, a potent antioxidant. Antioxidative property of sesamol protects against ironinduced organ damage, cyclophosphamide-induced hepatotoxicity, and stress-related mucosal disease.

\section{CONCLUSION}

Findings arising from the present study suggest that Sesame oil mitigates CCl4 induced CKD by activating Nrf2 and increases antioxidants thereby decreasing oxidative stress and attenuating KIM-1 expression in rats. The positive effect of sesame oil further substantiates previous studies and jointly postulate 
therapeutic value of Sesame oil in clinical conditions associated with CKD.

\section{ACKNOWLEDGMENT}

All authors have contributed significantly to this work.

\section{CONFLICT OF INTEREST}

No conflict of interest is declared

\section{REFERENCES}

1. Marzook EA, Abd El Moneim AE and Elhadary AA. Protective role of sesame oil against mobile base stationinduced oxidative stress. Journal of Radiation Research and Applied Sciences.2014; 7:1-6

2. Elhamalawy OH, Eissa FI, El Makawy AI and ELBamby MM. Bisphenol-A Hepatotoxicity and the Protective Role of Sesame oil in male mice. Jordan Journal of Biological Sciences. 2018; 11: 461-7

3. Jung TD, Choi SI, Choi SH, Cho BY, Sim WS, Xionggao H, Lee SJ, Park SJ, Kim DB, Kim YC, Lee JH and Lee $\mathrm{OH}$. Changes in the Anti-Allergic Activities of Sesame by Bioconversion. Nutrients 2018; 10: 210; doi: 10.3390/10020210.

4. Pathak N, Rai AK, Kumari R and Bhat KV. Value addition in sesame: A perspective on bioactive components for enhancing utility and profitability. Pharmacogn Rev. 2014; 8: 147-55.

5. Nasri $\mathrm{H}$ and Rafieian-Kopaei M. Protective effects of herbal antioxidants on diabetic kidney disease. Journal of Research in Medical Science. 2014; 19(1):82-3.

6. Nasri $H$ and Rafieian-Kopaei M. Tubular kidney protection by antioxidants. Iran J Publ Health. 2013; 42(10):1194-6.

7. Sahreen S, Rashid Khan M, Ali Khan R, Mohammad Alkreathy H. Protective effects of Carissa opaca fruits against CCl4-induced oxidative kidney lipid peroxidation and trauma in rat. Food Nutr Res. 2015; 59: 10.

8. Murray RK, Bender DA, Botham KM, Kennelly PJ, Rodwell VW and Weil PA. Harpers Illustrated Biochemistry (Lange Medical Book) 29th ed. McGrawHill Medical; 2014: 324-8.

9. Ogeturk M, Kus I, Colakoglu N, Zararsiz I. Caffeic acid phenethyl ester protects kidneys against $\mathrm{CCL}_{4}$ toxicity in rats. Journal of Ethnopharmacology. 2005; 97(2):273-80.

10. Elshater AA, Salman MM and Mohamed SA. The hepato-ameliorating effect of Solamun nigrum against $\mathrm{CCL}_{4}$ induced liver toxicity in albino rats. Egypt Acad J Biol Sci Physiol Mol Biol. 2013; 5: 55-66.

11. Mirazi N, Movassagh S and Rafieian-Kopaei M. The protective effect of hydro-alcoholic extract of mangrove (Avicennia marinaL.) leaves on kidney injury induced by carbon tetrachloride in male rats. Journal of Nephropathology. 2016; 5 (4):118-22.

12. Mazani M, Mahmoodzadeh Y, Chinifroush M, Banaei S, Rezagholizadeh L and Mohammadnia A. Renoprotective effects of the methanolic extract of Tanacetum parthenium against carbon tetrachloride-induced renal injury in rats. Avicenna Journal of Phytomedicen 2018; 8(4): 370-9.
13. Banan KSM, Houresfand M, Javanmard KR and Yaldagard E. Protective effects of Sophora pachycarpa root extract on $\mathrm{CCl}_{4}$ induced nephrotoxicity in male rat. Qom UMSJ. 2017; 11: 29-37.

14. Sherkatolabbasieh H, Hagh-Nazari L, Shafiezadeh S, Goodarzi N, Mehdi Zangeneh M, et al. Ameliorative effects of the ethanolic extract of Allium saralicum R.M. Fritsch on $\mathrm{CCl}_{4}$-induced nephrotoxicity in mice: $\mathrm{A}$ stereological examination. Arch Biol Sci. 2017; 69: 535-43.

15. Hamed H, Chaari F, Ghannoudi Z, ElFeki A, Chaabouni Ellouz S, et al. Beneficial Effects of Fermented Camel Milk by lactococcus lactis subsp cremoris on cardiotoxicity induced by Carbon Tetrachloride in mice. Biomed Pharmacother. 2018; 97: 107-14.

16. Rahmouni F, Hamdaoui L, Badraoui R and Rebai T. Protective effects of Teucrium polium aqueous extract and ascorbic acid on hematological and some biochemical parameters against carbon tetrachloride $\left(\mathrm{CCl}_{4}\right)$ induced toxicity in rats. Biomedicine \& Pharmacotherapy. 2017; 91: 43-8.

17. Nguyen T, Nioi P and Pickett CB. The Nrf2-antioxidant response element signaling pathway and its activation by oxidative stress. Journal of Biological Chemistry 2009; 284: 13291-5.

18. Li W, Khor TO, Xu C, Shen G, Jeong W-S, Yu S and Kong A. Activation of Nrf2-antioxidant signaling attenuates NF-KB-inflammatory response and elicits apoptosis. Biochem. Pharmacol. 2008; 76: 1485-9.

19. Rahman I, Biswas SK and Kirkham PA. Regulation of inflammation and redox signaling by dietary polyphenols. Biochemical Pharmacology. 2006; 72: 1439-52.

20. Liu C, Chien S, Hsu D, Periasamy S and Liu M. Curative effect of sesame oil in a rat model of chronic kidney disease. Nephrology 2015; 20 (12): 922-930.

21. Schulz CA, EngströmG, Nilsson J, Almgren P, Petkovic M, Christensson A, Nilsson PM, Melander O and OrhoMelander M. Plasma kidney injury molecule-1 (p-KIM1) levels and deterioration of kidney function over 16 years. Nephrology Dialysis Transplantation. 2019; 1-9.

22. Ichimura T, Bonventre JV, Bailly V, Wei H, Hession CA, Cate RL and Sanicola M. Kidney injury molecule-1 (KIM-1), a putative epithelial cell adhesion molecule containing a novel immunoglobulin domain, is upregulated in renal cells after injury. Journal of Biological Chemistry. 1998; 273: 4135-42.

23. Humphreys BD, Xu F, Sabbisetti V, Grgic I, Naini SM, Wang N, Chen G, Xiao S, Patel D, Henderson JM, Ichimura T, Mou S, Soeung S, McMahon AP, Kuchroo VK and Bonventre JV. Chronic epithelial kidney injury molecule-1 expression causes murine kidney fibrosis. Journal of Clinical Investigation 2013; 123: 4023-35.

24. Ruzena S, Silvester P, Jana N, Danica M, Veronika T, Miriam S, Katarina B. Effects of sesame oil in the model of adjuvant arthritis. Neuroendocrinol Lett 2009; 30(Suppl 1): 22-4.

25. Heejung Y, Sang HS and Young CK. The ethanolic extract of Juglans sinensis leaves and twigs attenuates CCl4-induced hepatic oxidative stress in rats. Pharmacognosy Magazine. 2015; 11(43): 533-9. 
26. American Veterinary Medical Association (AVMA) guidelines on Euthanasia 2013.

27. Draper $\mathrm{HH}$ and Hadley M. Malondialdehyde Determination as Index of Lipid Peroxidation. Methods Enzymol, 1990; 186, 421-31.

28. Carmagnol F, Sinet P, Rapin J, Jerome H. Glutathione Stransferase of human RBCs; assay, values in normal subjects and in two pathological circumstances: hyperbilirubinaemia and impaired renal function. Clinica Chemica Acta 1981; 117: 209-17.

29. Lowry OH., Rosebrough N J., Farr AL. and Randall RJ. Protein measurement with the folin phenol reagent. Journal of Biological chemistery 1951; 193: 265 -75.

30. Singh NP, McCoy MT, Tice RR and Schneider EL. A simple technique for quantitation of low levels of DNA damage in individual cells. Exp Cell Res 1988; 175:184-91.

31. Caroline R., Karin W., Lovisa B., Mehrafarin R., Marie W., Fengqing X., Anna A., Thomas W., Olof S., Anders J., Dagmar G., Per S., and Andrea C. Genetic Variations and mRNA Expression of NRF2 in Parkinson's Disease. Hindawi Parkinson's Disease 2017; 4020198.

32. Amin, R. P., Vickers, A. E., Sistare, F., Thompson, K. L., Roman, R. J., Lawton, M., Kramer, J., Hamadeh, H. K., Collins, J., Grissom, S., et al. Identification of putative gene based markers of renal toxicity. Environ. Health Perspect. 2004; 112, 465-79.

33. Wafaa M, Rasha A, Mennatullah A, Rowaida R and Maher A. The possible antidiabetic effects of vitamin D receptors agonist in rat model of type 2 diabetes. Molecular and Cellular Biochemistry 2019; 450: 105 - 12.

34. Khan A, Rahman MM, Tania M, Shoshee NF, Xu A and Chen H. Antioxidative potential of Duranta Repens (Linn.) Fruits against $\mathrm{H}_{2} \mathrm{O}_{2}$ induced cell death in vitro. Afr J Tradit Complement Altern Med. 2013; 10(3):436-41.

35. Hussain Z, EiThu H, Shuid AN, Kesharwani P, Khan $\mathrm{S}$ and Hussain F. Phytotherapeutic potential of natural herbal medicines for the treatment of mild-to-severe atopic dermatitis: A review of human clinical studies. Biomedicine \& Pharmacotherapy 2017; 93: 596-608.

36. Tirkey N, Pilkhwal S, Kuhad A, Kanwaljit C. Hesperidin, a citrus bioflavonoid, decreases the oxidative stress produced by carbon tetrachloride in rat liver and kidney. BMC Pharmacology 2005; 5: 2.
37. Ganie SA, Haq E and Hamid A. Carbon tetrachloride induced kidney and lung tissue damages and antioxidant activities of the aqueous rhizome extract of Podophyllum hexandrum. BMC Complementary \& Alternative Medicine 2011; 28: 17.

38. Jayakumar T, Sakthivel M, Thomas PA and Geraldine P. Pleurotus ostreatus, an oyster mushroom, decreases the oxidative stress induced by carbon tetrachloride in rat kidneys, heart and brain. Chemico-Biological Interactions 2008; 176: 108-20.

39. Hamed MA, Ali SA and El-Rigal NS. Therapeutic potential of ginger against renal injury induced by carbon-tetrachloride in rats. The Scientific World Journal $2012 ; 12$.

40. Hismiogullari AA, Hismiogullari SE and Karaca O. The protective effect of curcumin administration on carbon tetrachloride $\quad\left(\mathrm{CCl}_{4}\right)$-induced nephrotoxicity inrats. Pharmacological Reports 2015; 67 (3): 410-16.

41. Weber L, Boll M and Stampfl A. Hepatotoxicity and mechanism of action of haloalkanes: carbon tetrachloride as a toxicological model. Critical Reviews in Toxicology 2003; 33(2): 105-36.

42. Javed H, Khan MM and Khan A. S-Allyl cysteine attenuates oxidative stress associated cognitive impairment and neurodegeneration in mouse model of streptozotocin-induced experimental dementia of Alzheimer's type. Brain Research 2011; 1389: 133-42.

43. Ahmed S, Luo L, Namani A, Wang X and Tang X. Nrf2 signaling pathway: Pivotal roles in inflammation. Biochimica et Biophysica Acta (BBA) - Molecular Basis of Disease 2017; 1863(2): 585-97.

44. Rubio C, Hernández-Ruiz J, Martinez-Subiela S, Tvarijonaviciute A and Ceron J. Spectrophotometric assays for total antioxidant capacity (TAC) in dog serum: an update. BMC Vet Res 2016; 12: 166.

45. Kasibhatla S, Amarante-Mendes GP, Finucane D, Brunner T, Bossy-Wetzel E and Green DR. Analysis of DNA Fragmentation Using Agarose Gel Electrophoresis. CSH Protoc. 2006; 1.

46. van Timmeren MM1, van den Heuvel MC, Bailly V, Bakker SJ, van Goor H, Stegeman CA. Tubular kidney injury molecule-1 (KIM-1) in human renal disease. J Pathol. 2007; 212(2):209-17. 